\title{
Prevalence of Contralateral Hearing Aid Use in Adults with Cochlear Implants
}

\author{
Cintia Tizue Yamaguchi ${ }^{1}$ Maria Valéria Schmidt Goffi-Gomez ${ }^{1}$ \\ ${ }^{1}$ Division of Cochlear Implants, Department of Audiology, Clinic \\ Hospital of the Medicine High School of the University of São Paulo \\ (HCFMUSP), São Paulo/SP, Brazil \\ Address for correspondence Cintia Tizue Yamaguchi, Audiologist, 255 \\ Dr. Enéas de Carvalho Aguiar, 6th floor, Cerqueira César, São Paulo/SP \\ 05403-000, Brazil (e-mail: ct.yamaguchi@uol.com.br).
}

Int Arch Otorhinolaryngol 2013;17:370-374.

\begin{abstract}
Introduction The exclusive use of a cochlear implant $(\mathrm{Cl})$ in one ear allows patients to effectively hear speech in a quiet environment. However, in environments with competing noise, the processing of multiple sounds becomes complex. In an attempt to promote binaural hearing in a noninvasive manner, the use of a hearing aid in the nonimplanted ear is suggested for patients with a unilateral $\mathrm{Cl}$.

Aims To identify the prevalence of hearing aid use in the contralateral ear in adults who already have a $\mathrm{Cl}$; to determine the reasons why some patients do not use contralateral hearing aids (CHAs); and to analyze the effects of residual hearing in CHA users.

Materials and Methods This is a clinical study in 82 adult patients with $\mathrm{Cl}$ implants who responded to a questionnaire designed to determine current use of CHA.

Results In our patient sample, 70 CHA nonusers were identified. The prevalence of CHA users was determined to be $12 \%$ with a $95 \%$ confidence interval of 11 to $13 \%$. About $58.2 \%$ of the CHA nonusers reported a lack of noticeable benefit even after wearing hearing aids, and $23.6 \%$ reported not having received the option to use a CHA. CHA

\section{Keywords}

- cochlear implantation

- deafness

- hearing aids

- speech perception users had a pure tone average of $107-\mathrm{dB}$ hearing level, whereas $\mathrm{CHA}$ nonusers had a pure tone average of $117-\mathrm{dB}$ hearing level.

Conclusion The prevalence of the use of a $\mathrm{CHA}$ is low in our study. We attribute the low use of a CHA to either a lack of residual hearing or to a lack of benefit from the amplification.
\end{abstract}

\section{Introduction}

Deafness is a disability that affects individuals on variety of levels: social, emotional, and familial. As a result, deafness leads to significant lifestyle modifications.

Individual sound amplification devices (hearing aids) can mitigate hearing loss by amplifying sound input according to the needs of a patient. However, some patients with severe to profound hearing loss do not benefit from the use of hearing aids (due to a lack of sensory input) and cannot appropriately discriminate words and sentences.

The most efficient and widely used solution for this type of deficit is the placement of a cochlear implant $(\mathrm{CI})$. A CI is an electronic device that is implanted into the cochlea. Cls are indicated for the treatment of individuals with hearing loss who have severe to profound hearing loss and have not benefitted from the use of traditional hearing aids. The $\mathrm{CI}$ is an effective adjunct during the (re)habilitation of prelingual hearing-impaired children and postlingual hearing impaired adults. $^{1,2}$

The $\mathrm{CI}$ is usually implanted unilaterally. However, questions have been raised concerning issues related to unilateral hearing. For instance, unilateral hearing impairs the performance of speech perception in environments with a high level of ambient noise and negatively affects the performance of schoolchildren. ${ }^{3,4}$

The exclusive use of a $\mathrm{CI}$ in one ear (without the use of a contralateral hearing aid) allows patients to effectively hear received

September 4, 2012

accepted

June 6, 2013
Copyright $@ 2013$ by Thieme Publicações DOI http://dx.doi.org/ Ltda, Rio de Janeiro, Brazil

10.1055/s-0033-1352501. ISSN 1809-9777. 
speech in a quiet environment. However, in environments with competing noise, the processing of multiple sounds becomes difficult. In an attempt to promote binaural hearing in a noninvasive manner, the use of a hearing aid on the nonimplanted ear has been suggested for patients with a Cl. This approach has been referred to as bimodal stimulation. ${ }^{5}$

The International Consensus on Bilateral Cochlear Implants and Bimodal Stimulation recommends the application of bimodal stimulation in patients with residual hearing. ${ }^{6}$ It also proposes that bimodal stimulation may offer advantages with respect to speech perception in quiet and noisy environments and may contribute to sound localization.

The use of both CIs and hearing aids, rather than each of these alone, has shown an improvement in speech perception in noisy environments. ${ }^{7}$

Potts et al performed a study evaluating the concomitant use of Cls and hearing aids and the combined effect on speech recognition and localization. ${ }^{8}$ They suggested that the hearing aid must be designed using digital technology. They concluded that the combined benefits of a $\mathrm{Cl}$ and a contralateral digital hearing aid are greater than the benefits of using these alone.

Fitzpatrick and Leblanc conducted a study exploring the factors influencing the discontinuation contralateral hearing aid use in patients with a CI. ${ }^{9}$ They proposed that an "enhanced understanding of the factors influencing patients' decisions may help clinicians to modify their recommendations and counseling and thereby increase patient exposure to the potential benefits of combining acoustic and electrical stimulation."

Cullington and Zeng compared music perception, affective prosody discrimination, speaker identification, and speech recognition in presence of a competing talker in bimodal and bilateral $\mathrm{Cl}$ users. ${ }^{10}$ The aim of their study was to identify whether bilateral $\mathrm{CI}$ users or those with bimodal stimulation had the best aural performance. The authors found no difference between the groups.

However, this approach is not always followed in clinical practice. As a result, the potential stimulation of residual hearing of the opposite ear, which would allow the patients to benefit from binaural hearing, is often not attempted.

In the present study, we focus on the reasons why adults with Cls who have residual hearing do not use a hearing aid on the contralateral ear.

\section{Aims}

To identify the prevalence of the use of hearing aids in adults who received a $\mathrm{CI}$ at the Clinic Hospital of Medicine High School of the University of São Paulo (HCFMUSP); to determine the reasons why patients with CIs reported the nonuse of hearing aids and to elucidate the effects that residual hearing has on the decision to use a hearing aid in the contralateral ear.

\section{Materials and Methods}

The studied cohort included all of the patients who were implanted with a Cochlear Nucleus 22, Cochlear Nucleus 24, or Medel Combi 40 multichannel CIs from April 12, 1999 to July 18, 2007. Patients who met the following inclusion criteria were enrolled in the study: users of unilateral, multichannel CIs that met the HCFMUSP criteria ${ }^{11}$; prelingual or postlingual hearing-impaired adults (aged 18 years or older).

Three types of methods were used for data collection: inperson interviews (patients who were scheduled for programming of their $\mathrm{Cl}$ within the period of data collection); telephone interviews; and questionnaires sent via e-mail. In some cases, it was necessary to use more than method of contact.

A questionnaire ( - Table $\mathbf{1}$ ) was prepared and presented to all contacted patients. The questions were designed to encompass the following information: the use or nonuse of hearing aids in the contralateral ear, the reasons for use or nonuse, and whether the patients experienced any

Table 1 Hearing aid and cochlear implant $(\mathrm{Cl})$ use questionnaire

\begin{tabular}{|l|}
\hline Name: \\
\hline Age: \\
\hline Gender: \\
\hline Education: \\
\hline Cl side: date of Cl placement: \\
\hline $\begin{array}{l}\text { Pure tone average implanted side: not required } \\
\text { Pure tone average opposite side: not required }\end{array}$ \\
\hline $\begin{array}{l}\text { 1. Did you use hearing aids before receiving } \\
\text { the CI? If yes, in which ear? }\end{array}$ \\
\hline Yes ( ) No ( ) \\
\hline Right ear ( ) Left ear ( ) \\
\hline $\begin{array}{l}\text { 2. Do you use a hearing aid on the ear other than } \\
\text { the one with the CI? }\end{array}$ \\
\hline Yes ( ). Why? \\
\hline I was oriented to ( ) \\
\hline I have benefited from the hearing aid ( ) \\
\hline It contributes to the Cl ( ) \\
\hline Others: ( ) \\
\hline No ( ). Why? \\
\hline Lack of orientation ( ) \\
\hline Lack of benefit ( ) \\
\hline Lack of financial resources ( ) \\
\hline Others: ( ) \\
\hline 3. Do you miss or have difficulty in localizing sounds? \\
\hline Yes ( ) No ( ) \\
\hline Sometimes ( ) \\
\hline
\end{tabular}


Table 2 Demographic data

\begin{tabular}{|l|l|l|}
\hline & Group 1 & Group 2 \\
\hline$n$ & 72 & 10 \\
\hline Age $(\mathrm{y})$ & & \\
\hline Median & 42 & 37 \\
\hline Minimum & 18 & 22 \\
\hline Maximum & 70 & 63 \\
\hline Hearing aid users $(n)$ & 72 & 10 \\
\hline PTA contralateral $(\mathrm{dB})$ & & \\
\hline Median & 117.8 & 107.2 \\
\hline Minimum & 93 & 95 \\
\hline Maximum & 125 & 125 \\
\hline
\end{tabular}

Abbreviation: PTA, pure tone average.

difficulties in sound localization. The questionnaire included a section about consent for the use of the data in our study.

After completion of the questionnaire, data relating to the pure tone average (PTA) threshold of $500,1,000$, and 2,000 $\mathrm{Hz}$ were collected from medical records. ${ }^{12}$ A value of $125 \mathrm{~dB}$ was determined as the frequency threshold absent in audiometry for the calculation of the PTA threshold of the ear contralateral to the $\mathrm{CI}$.

In total, 137adults met the initial criteria for entry into our study. Of these, we were unable to contact 32, and 23 patients were excluded on the basis of the exclusion criteria. Therefore, the final total sample size was 82 patients (36 women and 46 men). The cohort was divided into two groups: group 1 comprised $\mathrm{CI}$ patients who were nonusers of a contralateral hearing aid; group 2 comprised $\mathrm{CI}$ patients who were users of a contralateral hearing aid (-Table $\mathbf{2}$ ).

The data were analyzed through descriptive statistics. Shapiro-Wilk test was used to assess the normality of the data. When normality was observed, a $t$ test was used; otherwise, parametric Mann-Whitney test was applied. Data were considered statistically significant if $p$ values were $<0.05$.

\section{Results}

The prevalence of individuals with CIs who were using hearing aids in the contralateral ear was $12 \%$ (95\% confidence interval, 11 to 13\%; - Tables 2 and $\mathbf{3}$ ).
Table 4 Reasons for using hearing aids contralateral to the $\mathrm{Cl}$ and PTA threshold (in decibels hearing level) of patients who reported the reasons

\begin{tabular}{|l|l|l|l|l|}
\hline & \multirow{2}{*}{$\mathbf{n}$} & \multirow{2}{*}{$\%$} & \multicolumn{2}{|c|}{ PTA (dB) } \\
\cline { 4 - 5 } & & & Mean & SD \\
\hline Helps to listen better & 7 & 70 & 103.14 & 6.36 \\
\hline Instructed to use & 1 & 10 & 100 & - \\
\hline $\begin{array}{l}\text { Binaural advantage } \\
\text { and instructed }\end{array}$ & 2 & 20 & 125 & - \\
\hline Total & 10 & 100 & - & - \\
\hline
\end{tabular}

Abbreviations: $\mathrm{Cl}$, cochlear implant; PTA, pure tone average; SD, standard deviation.

Table 5 Between-group statistical analysis of pure-tone average threshold (in decibels hearing level)

\begin{tabular}{|l|l|l|l|}
\hline & Group 1 & Group 2 & $p$ \\
\hline$n$ & 72 & 10 & \multirow{2}{*}{0.0051} \\
\cline { 1 - 3 } Mean & 117.76 & 107.2 & \\
\cline { 1 - 3 } Standard deviation & 9.46 & 10.77 & \\
\cline { 1 - 3 } Median & 125 & 103 & \\
\hline
\end{tabular}

During the interview, the participants were asked about their difficulties with sound localization. In Group 1, a majority of the participants noted difficulty with sound localization in environments with background noise. The difference between groups 1 and 2 was not statistically significant (- Table 4).

We observed that $70 \%$ of the patients reported improvement in their hearing ability with the combined use of $\mathrm{CI}$ and a contralateral hearing aid; $20 \%$ of the patients benefited from bimodal stimulation with $125 \mathrm{~dB}$ of residual hearing (-Table 5).

The Mann-Whitney test showed a significant difference in the PTA thresholds of the two groups ( $p=0.0051$; - Table 6 ).

\section{Discussion}

Currently, bimodality ( $\mathrm{CI}$ combined with a contralateral hearing aid) is fundamental with regard to the possibility of achieving binaural hearing in patients with bilateral, severe to

Table 3 Difficulty of sound localization of studied groups referred during interview

\begin{tabular}{|c|c|c|c|c|c|}
\hline \multirow[b]{2}{*}{ Difficulty in the sound localization } & \multicolumn{2}{|c|}{ Group 1} & \multicolumn{2}{|c|}{ Group 2} & \multirow[t]{2}{*}{$p$} \\
\hline & $n$ & $\%$ & $n$ & $\%$ & \\
\hline No & 14 & 19.4 & 2 & 20 & 0.9693 \\
\hline Only in environments & 34 & 47.2 & 2 & 20 & 0.0851 \\
\hline Yes & 17 & 23.6 & 3 & 30 & 0.6988 \\
\hline Data not available & 7 & 9.7 & 3 & 30 & 0.2249 \\
\hline Total & 72 & 100 & 10 & 100 & \\
\hline
\end{tabular}


Table 6 Distribution of the pure tone average threshold (in decibels hearing level) by intervals in both studied groups

\begin{tabular}{|c|c|c|c|c|c|c|c|c|c|}
\hline \multirow[b]{2}{*}{$\mathrm{dB}$} & \multicolumn{4}{|c|}{ Group 1} & \multicolumn{4}{|c|}{ Group 2} & \multirow[t]{2}{*}{$p$ value } \\
\hline & $n$ & $\%$ & Main & SD & $n$ & $\%$ & Main & SD & \\
\hline $90-100$ & 6 & 8.50 & 96 & 2.76 & 4 & 40.00 & 98.75 & 2.5 & 0.184 \\
\hline $101-110$ & 8 & 11.30 & 106,13 & 3.6 & 3 & 30.00 & 104 & 2.65 & 0.3337 \\
\hline $111-120$ & 20 & 28.20 & 115,7 & 2.68 & 1 & 10.00 & 115 & - & - \\
\hline$>120$ & 37 & 52.10 & 124,89 & 0.66 & 2 & 20.00 & 125 & 0 & 0.9075 \\
\hline Total & 71 & & & & 10 & & & & \\
\hline
\end{tabular}

Abbreviation: SD, standard deviation.

profound, hearing loss. This combination is generally used in patients who have residual hearing and/or who have a good response with a hearing aid in the nonimplanted ear. Several studies have been conducted on the subject with the aim to expand upon the knowledge already known about bimodality. ${ }^{1,2,5-7}$

Several researchers have concluded that sound localization can be improved through the use of a $\mathrm{CI}$ combined with a contralateral hearing aid. ${ }^{5,8,13}$ - Table 2 displays the responses of the participants when questioned about the difficulty of sound localization. The responses relating to sound localization were similar in both groups. Moreover, in our study there were participants who did not describe difficulties in sound localization; despite being unilateral CI users without a contralateral hearing aid. Dunn et $\mathrm{al}^{14}$ published a study in which only 2 of the 12 patients evaluated for sound localization were able to localize sound with a $\mathrm{CI}$ combined with a contralateral hearing aid. The authors also reported that patient effort is a factor when it comes to improving the integration of sensory information (and improved sound localization) provided by the combined use of a $\mathrm{CI}$ and a hearing aid. Their conclusion concerning the importance of patient effort is supported by the following factors: (1) sound localization is a central auditory nervous system process, and (2) some people are able to integrate information from two ears (improving speech perception and sound localization) and others (with similar, two-ear capabilities) are not.

The patient responses concerning the reasons for the use of a $\mathrm{CI}$ in conjunction with a hearing aid are presented in - Table 3. These data show that most patients (70\%) reported that sound quality was better with the combined use of a $\mathrm{CI}$ and a hearing aid. The data also show that these patients have PTA contralateral to a CI capable of offering acoustic information that contributes to sound quality. Some authors have suggested a theory for how the bimodal condition provides superior information: acoustic amplification through a contralateral hearing aid provides necessary, lowfrequency information, which is not provided by the $\mathrm{CI}$ alone. . $^{15,16}$

We believe that the level of residual hearing plays an important role in bimodal adaptation. PTA comparison between group 1 and group 2 was statistically significant $(p=0.0051$; - Table 4$)$. The group of patients with better residual hearing was the group that reported the combined use of a CI with a contralateral hearing aid.

Several other authors have suggested that residual hearing contributes to the effectiveness of bimodality. ${ }^{5,6,8,13}$ However, Ching et al found no statistical significance when comparing the PTA in children on the basis of tests for sound localization and speech perception and questionnaires given to parents of the children. ${ }^{17}$ The authors mentioned that the contributions from residual hearing were found to be associated with the individual. Therefore, the following questions remain: (1) Is the success of bimodal hearing directly dependent upon the residual hearing of patients? (2) Is the success of bimodal hearing more dependent upon the integration of the central, auditory, nervous system? (3) Is the success of bimodal hearing associated with both of these factors? Potts et al stated that it "is recommended that unilateral CI recipients, with measurable unaided hearing thresholds, be fit with a hearing aid." 8

Continuing with the topic of residual hearing, - Table 5 shows the distribution of residual hearing according to groups. It was observed that the percentage of subjects with residual hearing up to $110 \mathrm{~dB}$ was higher in group 2, and the percentage of individuals with residual hearing up to $110 \mathrm{~dB}$ was lower in group 1. Interestingly, all of the patients in group 2 used hearing aids in both ears prior to their $\mathrm{CI}$ placement. In addition, most of the patients in group $1 \mathrm{did}$ not use hearing aids in both ears prior to their CI placement. This leads us to conclude that the use of hearing aids prior to the placement of a $\mathrm{CI}$ may have some influence on the central auditory nervous system integration, such that, when adapted to bimodality, integration and plasticity of the auditory pathways already exist.

\section{Conclusions}

In our clinic, we were able to identify that the prevalence of the use of a contralateral hearing aid in adults with $\mathrm{CI}$ was $12 \%$. One of the reported reasons for not using a contralateral hearing aid in conjunction with a $\mathrm{CI}$ was a lack of perceived benefit from the hearing aid. The residual hearing of the $\mathrm{CI}$ patients who use a contralateral hearing aid was higher (107-dB hearing level) than that of the $\mathrm{CI}$ patients who do not use a contralateral hearing aid (117-dB hearing level). 


\section{References}

1 Bento FR, Neto RB, Castilho AM, Gómez VG, Giorgi SB, Guedes MC. Resultados auditivos com implante coclear multicanal em pacientes submetidos à cirurgia no Hospital das Clínicas da Faculdade de Medicina da Universidade de São Paulo. Braz J Otorhinolaryngol 2004;70:632-637

2 Bevilacqua MC, Filho OC, Nascimento LT, Banhara MR. Evaluation of the combined use of hearing aid and cochlear implants in adults. Disturb Comun 2004;16:27-33

3 Feuerstein JF. Monaural versus binaural hearing: ease of listening, word recognition, and attentional effort. Ear Hear 1992; 13:80-86

4 Lieu JE. Speech-language and educational consequences of unilateral hearing loss in children. Arch Otolaryngol Head Neck Surg 2004;130:524-530

5 Ching TY, Incerti P, Hill M, van Wanrooy E. An overview of binaural advantages for children and adults who use binaural/bimodal hearing devices. Audiol Neurootol 2006;11(Suppl 1):6-11

6 Offeciers E, Morera C, Müller J, Huarte A, Shallop J, Cavallé L. International consensus on bilateral cochlear implants and bimodal stimulation. Acta Otolaryngol 2005;125:918-919

7 Hamzavi J, Pok SM, Gstoettner W, Baumgartner WD. Speech perception with a cochlear implant used in conjunction with a hearing aid in the opposite ear. Int J Audiol 2004;43:61-65

8 Potts LG, Skinner MW, Litovsky RA, Strube MJ, Kuk F. Recognition and localization of speech by adult cochlear implant recipients wearing a digital hearing aid in the nonimplanted ear (bimodal hearing). J Am Acad Audiol 2009;20:353-373
9 Fitzpatrick EM, Leblanc S. Exploring the factors influencing discontinued hearing aid use in patients with unilateral cochlear implants. Trends Amplif 2010;14:199-210

10 Cullington HE, Zeng FG. Comparison of bimodal and bilateral cochlear implant users on speech recognition with competing talker, music perception, affective prosody discrimination, and talker identification. Ear Hear 2011;32:16-30

11 Gomez MVSG, Guedes MC, Sant'Anna SBG, et al. Medical and audiological selection criteria and evaluation for cochlear implants candidates: HC-FMUSP protocol. Int Arch Otorhinolaryngol 2004;8: 295-303

12 Davis H, Silverman RS. Hearing and Deafness. 3rd ed. New York: Holt, Rinehart \& Wilson; 1970

13 Seeber UB, Baumann U, Fastl H. Localization ability with bimodal hearing aids and bilateral cochlear implants. J Acoust Soc Am 2004;116:1699-1709

14 Dunn CC, Tyler RS, Witt SA. Benefit of wearing a hearing aid on the unimplanted ear in adult users of a cochlear implant. J Speech Lang Hear Res 2005;48:668-680

15 Kong YY, Stickney GS, Zeng FG. Speech and melody recognition in binaurally combined acoustic and electric hearing. J Acoust Soc Am 2005;117(3 Pt 1):1351-1361

16 Vandali AE, Sucher C, Tsang DJ, McKay CM, Chew JW, McDermott HJ. Pitch ranking ability of cochlear implant recipients: a comparison of sound-processing strategies. J Acoust Soc Am 2005;117:3126-3138

17 Ching TY, Psarros C, Hill M, Dillon H, Incerti P. Should children who use cochlear implants wear hearing aids in the opposite ear? Ear Hear 2001;22:365-380 